$$
\text { NASAICR.-97- } 207783 \quad 1 / 10 \cdot R
$$

\title{
WORKSHOP ON PARENT-BODY AND NEBULAR MODIFICATION OF CHONDRITIC MATERIALS
}

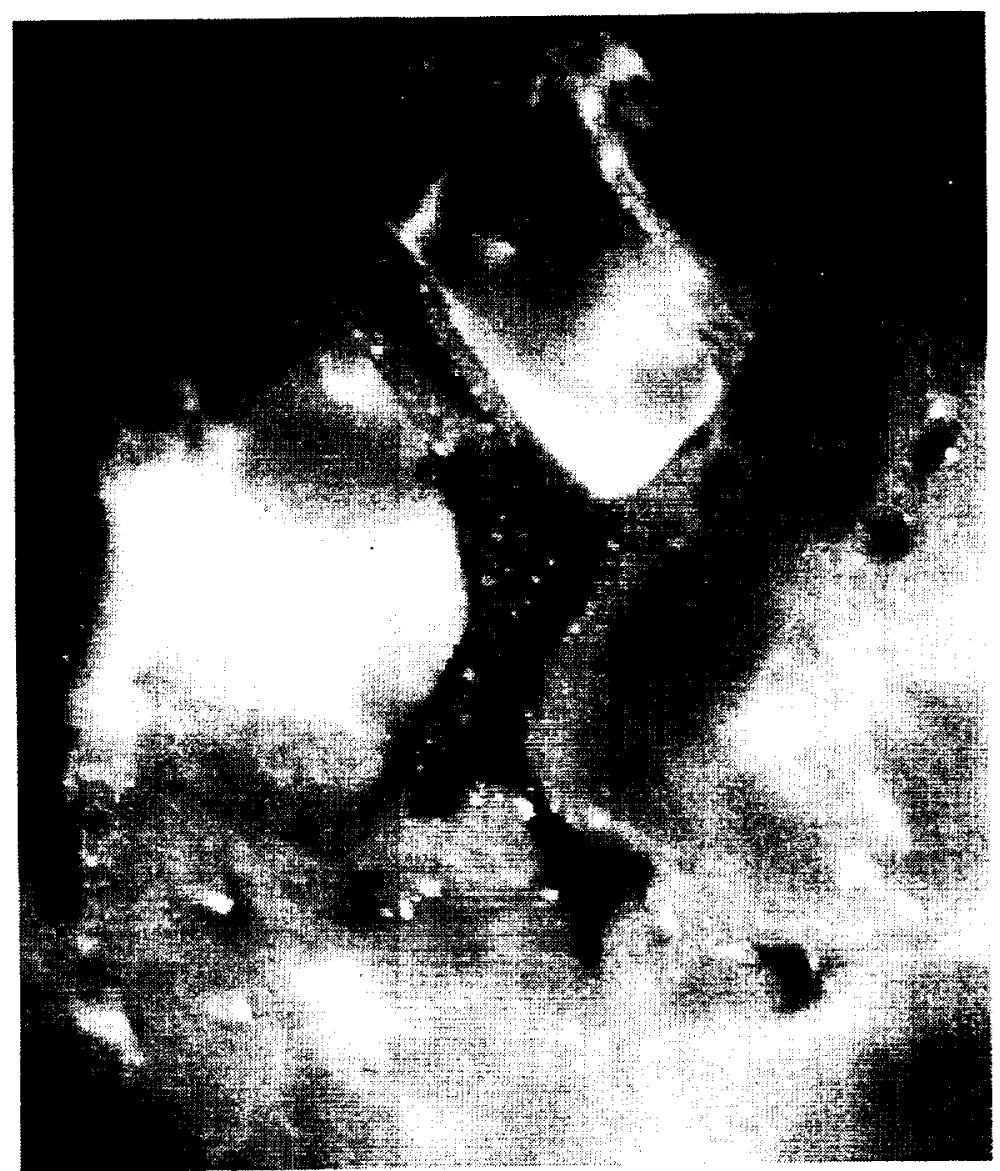

LPI Technical Report Number 97-02, Part 2

Lunar and Planetary Institute 3600 Bay Area Boulevard Houston TX 77058-1113 LPI/TR--97-02, Part 2 


\title{
WORKSHOP ON
}

\section{PARENT-BODY AND NEBULAR MODIFICATION \\ OF CHONDRITIC MATERIALS}

\author{
Edited by \\ M. E. Zolensky, A. N. Krot, and E. R. D. Scott
}

Held at

Maui, Hawai'i

July $17-19,1997$
Hosted by
Hawai'i Institute of Geophysics and Planetology
University of Hawai'i
Sponsored by
Lunar and Planetary Institute
University of Hawai'i
National Aeronautics and Space Administration
NASA Integrated Systems Network

Lunar and Planetary Institute 3600 Bay Area Boulevard Houston TX 77058-1 113

LPI Technical Report Number 97-02, Part 2

LPI/TR--97-02, Part 2 


\section{Compiled in 1998 by \\ LUNAR AND PLANETARY INSTITUTE}

The Institute is operated by the Universities Space Research Association under Contract No. NASW-4574 with the National Aeronautics and Space Administration.

Material in this volume may be copied without restraint for library, abstract service, education, or personal research purposes; however, republication of any paper or portion thereof requires the written permission of the authors as well as the appropriate acknowledgment of this publication.

This report may be cited as

Zolensky M. E., Krot A. N., and Scott E. R. D., eds. (1998) Workshop on Parent-Body and Nebular Modification of Chondritic Materials. LPI Tech. Rpt. 97-02, Part 2, Lunar and Planetary Institute, Houston. 18 pp.

This report is distributed by

ORDER DEPARTMENT

Lunar and Planetary Institute

3600 Bay Area Boulevard

Houston TX 77058-1113

Mail order requestors will be invoiced for the cost of shipping and handling.

Cover: Olivine with amorphous olivine rims in a primitive (?) clast in the Ningqiang chondrite.

View measures $1 \mu \mathrm{m}$ across. 


\section{Preface}

On July 17-19, 1997, a three-day Workshop on Parent Body and Nebular Modification of Chondritic Materials was held on Maui, Hawai'i. The workshop was hosted by the Hawai'i Institute of Geophysics and Planetology, University of Hawai'i, and sponsored by the Lunar and Planetary Institute, University of Hawai'i, National Aeronautics and Space Administration, and NASA Integrated Systems Network.

The purpose of the workshop was to advance our understanding of solar nebula and asteroidal processes from studies of modification features in chondrites and interplanetary dust particles. As reflected in the program contained in this volume, the workshop included five regular sessions, a summary session, and a poster session. Twenty-three posters and 42 invited and contributed talks were presented. Part 1 of this report contains the abstracts of these presentations.

The focus of the workshop included (1) mineralogical, petrologic, chemical, and isotopic observations of the alteration mineralogy in interplanetary dust particles, ordinary and carbonaceous chondrites, and their components (Ca-Al-rich inclusions, chondrules, and matrix) to constrain the conditions and place of alteration; (2) sources of water in chondrites; (3) the relationship between aqueous alteration and thermal metamorphism; (4) short-lived radionuclides, ${ }^{26} \mathrm{Al},{ }^{53} \mathrm{Mn}$, and ${ }^{129} \mathrm{I}$, as isotopic constraints on timing of alteration; (5) experimental and theoretical modeling of alteration reactions; and $(6)$ the oxidation state of the solar nebula.

There were approximately 140 participants at the workshop, probably due in part to the timeliness of the workshop goals and the workshop location. In the end few new agreements were achieved between warring factions, but new research efforts were forged and areas of fruitful future exploration were highlighted. Judged by these results, the workshop was successful.

The workshop conveners wish to acknowledge the critical role played by the organizing committee, who contributed so greatly to the success of the event: Addi Bischoff (Institut für Planetologie, Münster), Pat Cassen (NASA Ames Research Center), Bruce Fegley (Washington University), Klaus Keil (University of Hawai'i), John Kerridge (University of Califomia, San Diego), Hiroko Nagahara (University of Tokyo), Herbert Palme (Universität zu Köln), Sara Russell (Smithsonian Institution), Kazushige Tomeoka (Kobe University).

Logistical, administrative, and publications support for this workshop were provided by the staff of the Publications and Program Services Department, Lunar and Planetary Institute.

Alexander Krot

Ed Scott

Michael Zolensky 
. 


\section{Program}

Thursday, July 17, 1997

\section{AQUEOUS ALTERATION: NEBULAR AND ASTEROIDAL 8:30 a.m.-12:00 noon Makena Salon}

Chairs: L. B. Browning and M. E. Zolensky

Zolensky M. E.* [15 minutes] Aqueous Alteration of Carbonaceous Chondrites: Evidence for Asteroidal Alteration

Bischoff A.* [15 minutes] Aqueous Alteration of Carbonaceous Chondrites: Evidence for Preaccretionary Alteration

Browning L. B.* [10 minutes] A Search for Accretionary Textures in CM Chondrites

Hanowski N. P.* Brearley A. J. [10 minutes] Iron-rich Aureoles as Recorders of In Situ Aqueous Alteration in the CM Carbonaceous Chondrites Murray, Murchison, and Allan Hills 81002

Break (10:00-10:20 a.m.)

Deloule E. Doukhan J.-C. Robert F.* [10 minutes] Interstellar Hydroxyls in Meteoritic Chondrules: Implications for the Origin of Water in the Inner Solar System

Tomeoka K.* [15 minutes] Aqueous Alteration and Dehydration Processes in the Carbonaceous Chondrites

Akai J.* Tari S. [10 minutes] Thermally Metamorphosed Antarctic CM and CI Carbonaceous Chondrites in Japanese Collections, and Transformation Processes of Phyllosilicates

Hutchison R.* Alexander C. M. O'D. Bridges J. C. [10 minutes] Elemental Redistribution by Aqueous Fluids in Unequilibrated Ordinary Chondrites: Tieschitz and Semarkona Compared

Scott E. R. D.* Krot A. N. Browning L. B. [15 minutes] Asteroidal Modification of $C$ and $O$ Chondrites: Myths and Models

* Designates speaker

[ ] Length of presentation 


\section{ALTERATION OF CV3 CHONDRITES: NEBULAR OR ASTEROIDAL? 1:30-5:00 p.m. \\ Makena Salon \\ Chairs: G. J. MacPherson and S. Weinbruch}

Krot A. N.* Scott E. R. D. Zolensky M. E. [20 minutes]

Mineralogical and Chemical Modification of CV3 Chondrites During Fluid-assisted Metamorphism in the CV3 Asteroid

Palme H.* [15 minutes]

Oxygen-Fugacity Indicators in Carbonaceous Chondrites: Parent-Body Alteration or High-Temperature Nebular Oxidation?

Hua X.* Buseck P. R. [10 minutes]

Fayalite Halos Within Forsterites from Carbonaceous Chondrites

MacPherson G. J.* Davis A. M. [15 minutes]

Parent-Body Metamorphism of CV3 Chondrites: Counterarguments Based on Accretionary Rims and Calcium-Aluminum-rich Inclusions

Break (3:10-3:30 p.m.)

Swindle T. D.* [10 minutes]

Do Iodine-Xenon Ages Tell Us Anything About the Site of Secondary Alteration?

Weisberg M. K.* Prinz M. [10 minutes]

Fayalitic Olivine in CV3 Chondrite Matrix and Dark Inclusions: A Nebular Origin

Ikeda Y.* Kimura M. [10 minutes]

Anhydrous Alteration of Allende Chondrules in the Solar Nebula

Petaev M. I.* Mironenko M. V. [10 minutes]

Thermodynamic Modeling of Aqueous Alteration in CV Chondrites

Nomura K.* Miyamoto M.

Experimental Study on Formation of Secondary Minerals in Calcium-Aluminum-rich Inclusions in Carbonaceous Chondrites 


\section{POSTER SESSION \\ 5:15-7:30 p.m. \\ Hale Makena}

Bland P. A. Sephton M. A. Bevan A. W. R. Berry F. J. Cadogan J. M. Pillinger C. T. Magnetite in Vigarano: An Iron-57 Mössbauer Spectroscopy Study

Bourot-Denise M. Zanda B. Hewins R.

Metamorphic Transformations of Opaque Minerals in Chondrites

Bridges J. C.

Chlorine-bearing Melt Inclusions in Olivine from Unequilibrated Ordinary Chondrites

Cyr K. E. Hutson M. L. Lunine J. I.

Effect of Revised Nebular Water Distribution on Enstatite Chondrite Formation

Goodrich C. A.

The Chondrite-Achondrite Transition: Decoupling of Oxygen Isotope and Geochemical Changes

Grady M. M. Batchelder M. Cressey G. Genge M. J.

Progressive Alteration of CM2 Chondrite Matrixes: Determining Relative Phyllosilicate Contents by X-Ray Diffraction

Hallenbeck S. L. Nuth J. A. Rietmeijer F. J. M.

Thermal Quenching of Silicate Grains in Protostellar Sources

Hashizume K. Sugiura N.

Transportation of Gaseous Elements and Their Isotopes in a Thermally Evolving

Chondritic Planetesimal

Hong Y. Fegley B. Jr.

An Experimental Study of Magnetite Formation in the Solar Nebula

Horanyi M.

Lightning and Shock Heating as Candidate Processes for Chondrule Formation

Kimura M. Ikeda Y.

Relationship Between Anhydrous and Aqueous Alterations in CV3 Chondrites

Lauretta D. S. Lodders K. Fegley B. Jr.

The Alteration of Nickel-bearing Sulfides During Thermal Metamorphism on Ordinary Chondrite Parent Bodies

Lofgren G. E.

Fragmental Aggregation in the Nebula: A Basic Nebular Process 
Norman M. D.

Impact Melting, Metal-Silicate Fractionation, and Volatile-Element Mobility on the L-Chondrite Parent Body

Reid A. M.

Antarctic LL Chondrites

Rivkin A. S. Britt D. T. Lebofsky L. A. Howell E. S. Clark B. E.

Correlation of Water of Hydration with Diameter in Tholen $E$-class and $M$-class Asteroids

Sanders I. S.

Evidence from the Bovedy (L3) Chondrite for Impact-generated Chondrules

Stelzner Th. Heide K.

Evolved Gas Analysis: A Technique to Study Cosmic Alteration of Chondrites?

Stephan T. Rost D. Jessberger E. K.

Volatile-Element Enrichments in Interplanetary Dust Due to Nebular Processes?

Wolf S. F. Lipschutz M. E.

Volatile Trace-Element Composition and Shock in Equilibrated H Chondrites

Yanai $\mathrm{K}$.

A Unique Chondrule Consisting of Forsterite and Clear Glass Groundmass with Compositional Zoning in Ordinary Chondrites

Friday, July 18, 1997

\section{MODIFICATION OF CHONDRITIC COMPONENTS: WHEN, WHERE, AND HOW? \\ 8:30 a.m.-12:00 noon \\ Makena Salon}

Chairs: J. N. Grossman and S. S. Russell

Huss G. R.* [15 minutes]

Presolar Grains as Tracers of Nebular and Parent-Body Processing of Chondritic Material

Russell S. S.* MacPherson G. J. [15 minutes]

Alteration of Calcium-Aluminum-rich Inclusions: Times and Places

Wark D. A.* [10 minutes]

Conditions for Forming Calcium-Aluminum-Rich-Inclusion Rim Layers: Preliminary Experiments 
Brearley A. J.* [20 minutes]

Unraveling Nebular and Parent-Body Effects in Chondrite Matrixes: Mineralogical and Compositional Constraints

Greshake A.* [10 minutes]

Primitive Matrix Components of the Unique Carbonaceous Chondrite Acfer 094: Clues to Their Origin

Break (10:30-10:50 a.m.)

Rietmeijer F. J. M.* Guofei F. Karner J. M. [15 minutes] Alteration of Presolar Dust Based on Transmission Electron Microscope/Analytical Electron Microscope Studies of Chondritic Interplanetary Dust Particles and Nonequilibrium Simulation Experiments

Grossman J. N.* Alexander C. M. O'D. Wang J. [15 minutes] Chemical Alteration of Chondrules on Parent Bodies

Jones R. H.* [10 minutes] Alteration of Plagioclase-rich Chondrules in $\mathrm{CO} 3$ Chondrites: Evidence for Late-stage Sodium and Iron Metasomatism in a Nebular Environment

\section{MINERALOGICAL AND ISOTOPIC CONSTRAINTS ON THE SOLAR NEBULA AND ASTEROIDAL PROCESSING OF CHONDRITIC MATERIALS 1:30-5:00 p.m. Makena Salon}

Chairs: A. El Goresy and J. A. Nuth

Zanda B.* Yu Y. Bourot-Denise M. Hewins R. [15 minutes] The History of Metal and Sulfides in Chondrites

Fegley B. Jr.* [15 minutes]

Theoretical Models and Experimental Studies of Gas-Grain Chemistry in the Solar Nebula

Wasson J. T.* [15 minutes] Oxygen Fugacity in the Solar Nebula

Clayton R. N.* [15 minutes] Use of Oxygen Isotopes to Constrain the Nebular and Asteroidal Modification of Chondritic Materials

Break (3:20-3:40 p.m.) 
Wadhwa M.* Zinner E. K. Crozaz G. [10 minutes] Manganese-Chromium Systematics in Sulfides of Unequilibrated Enstatite Chondrites: Parent-Body vs. Nebular Processing and Implications for Accretion Times

Lodders K.* Fegley B. Jr. [10 minutes]

What Do Enstatite Meteorites Tell Us About the Solar Nebula?

Weinbruch S.* Palme H. Spettel B. Steele I. M. [10 minutes]

Refractory Forsterite in Carbonaceous Chondrites: An Unaltered Condensate from the Solar Nebula

Nagahara H.* [10 minutes]

Evaporation Behavior of Minerals and Silicate Melt in Vacuum and in Hydrogen Gas

Nuth J. A.* Withey P. A. [10 minutes]

Formation of Single-Domain Iron Particles: Implications for the Nebula

Saturday, July 19, 1997

\section{PETROLOGIC AND CHEMICAL CONSTRAINTS ON ACCRETION AND ALTERATION OF CHONDRITIC MATERIALS 8:30-10:10 a.m. Makena Salon}

Chairs: R. H. Jones and D. S. Lauretta

Hutcheon I. D.* [15 minutes]

Chronologic Constraints on Secondary Alteration Processes

Cuzzi J. N.* Hogan R. Dobrovolskis A. Paque J. [10 minutes]

Turbulent Size Selection and Concentration of Chondrule-sized Objects: Reynolds Number Invariance and Implications

Kurat G.* [10 minutes]

The Meteorite Parent-Body Alteration Model and the Incompatible Reality

Sears D. W. G.* Akridge G. [10 minutes]

Nebular or Parent-Body Alteration of Chondritic Material: Neither or Both?

Lipschutz M. E.* [10 minutes]

Nebular and Parent-Body Processes in Chondrites: Labile Trace Elements as Indicators and Thermometers

Break (10:10-10:30 a.m.) 


\title{
WHAT HAVE WE LEARNED ABOUT ASTEROIDAL AND NEBULAR PROCESSING OF CHONDRITIC MATERIALS, WHAT REMAINS UNRESOLVED, WHAT MUST BE DONE? 10:30 a.m.-12:15 p.m. \\ Makena Salon
}

Chairs: H. Palme and J. T. Wasson

\author{
Cassen P.* [20 minutes] \\ Summary \\ Kerridge J.* [20 minutes] \\ Summary
}

Workshop Adjourns (12:15 p.m.) 



\section{Contents}

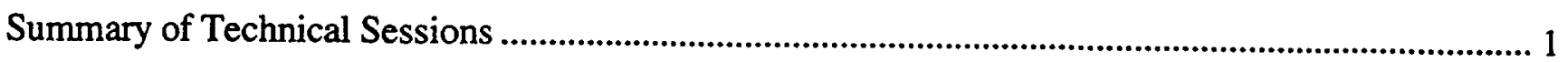

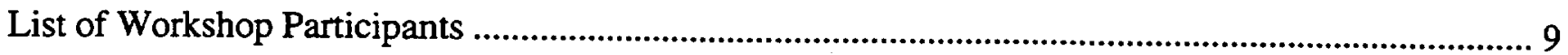





\section{Summary of Technical Sessions}

\section{AQUEOUS ALTERATION: NEBULAR AND ASTEROIDAL}

\author{
Summarized by M. E. Zolensky and L. Browning
}

The first workshop session was intended to present participants with general summaries of the issues pitting asteroidal vs. nebular origin for aqueous alteration assemblages observed in chondrites.

$M$. Zolensky led off with a brief description of the secondary minerals (phyllosilicates, hydroxides, tochilinites, sulfates, oxides, and carbonates) and their textural occurrences in carbonaceous chondrites, which are believed to have resulted from the action of aqueous alteration in an asteroidal environment. The occurrence of these minerals in veins, open space fillings, and chondrule pseudomorphs indicates that they formed in the presence of aqueous solutions in consolidated materials, i.e., asteroids or planetesimals. Additional arguments favoring asteroidal setting come from thermodynamic analyses of hydration reactions showing that phyllosilicate formation is kinetically prohibited in the solar nebula (Fegley, this workshop). Carbonates can be stabilized only at very high $\mathrm{f}_{\mathrm{CO}_{2}}$, which are unlikely to have been reached in the solar nebula (Armstrong et al., 1982). One contentious issue raised during this presentation concerned magnetite crystals. There are several magnetite morphologies, specifically spherulites, placquettes (spiral dislocation growth forms) and framboids, that have been ascribed to both asteroidal and nebular formation processes. Discussion revealed that the origin of these magnetites remains poorly constrained, requiring new thought and experiments.

A. Bischoff presented an overview of the evidence for the preaccretionary formation of some secondary minerals. The supporting evidence includes (1) the extreme heterogeneity of alteration phases, e.g., apparently unaltered grains sitting within matrix next to clay aggregates; and (2) distinct compositional discontinuities between altered and adjacent unaltered phases and nearby altered phases. Bischoff suggested that these observations are consistent with the Metzler et al. (1992) model of aqueous alteration. According to this model some aqueous alteration occurred in relatively small and uncompacted precursor planetesimals that were subsequently dispersed by collisions prior to the accretion of the meteorite parent asteroid. This episode of aqueous alteration was overprinted by late-stage aqueous alteration in asteroidal environment. A critical issue here is just what the minimum wet asteroid size could be, given the remaining great uncertainties concerning the heat source that provided liquid water. A final point that arose from this talk was the discussion of just what meteoriticists mean by "nebula": Clearly there were several phases in nebula evolution, as well as asteroidal accretion, and just as clearly we must henceforth be more specific in our descriptions of "nebular" and "preaccretionary" processes.

An important proposal by Metzler et al. (1992) that nebular accretionary textures are well preserved in some CM2 chondrites (e.g., Y 791198) was challenged by L. Browning. Browning presented the evidence that all $\mathrm{CM}$ chondrites have seen significant brecciation, even Y 791 198, and that any accretionary textures are rarely, if ever, preserved. During the discussion, J. Wasson pointed out that many chondritic materials, including matrix and chondrule rims, have relatively low porosities ( $<5 \%)$, too low to have formed in a microgravity environment.

N. Hanowski and A. Brearley described Fe-enriched and S-, Mg-, Si-depleted aureoles around altered metal inclusions in several CM chondrites. The compositional behavior of the altered metal inclusions (depletion in $\mathrm{Fe}$ and enrichment in $\mathrm{S}, \mathrm{Mg}$, and $\mathrm{Si}$ ) appears to complement the behavior of their surrounding aureoles. The aureoles commonly enclose adjacent chondrules, chondrule fragments, and fine-grained material. These observations and mass-balance calculations indicate that aureole formation took place in situ by element mobilization into and out of altered metal inclusions over millimeter-scale distances after agglomeration, brecciation, and lithification of $\mathrm{CM}$ materials, i.e., in an asteroidal environment.

F. Robert and coauthors focused on sources of water in chondritic meteorites. Their ion-probe study of $\mathrm{H}$ isotopes revealed that aqueously altered mesostasis and hydrated pyroxene phenocrysts in ordinary chondrite chondrules have different $\mathrm{D} / \mathrm{H}$ ratios ( $150 \times 10^{-6}$ and up to $460 \times 10^{-6} \mathrm{re}$ spectively). Robert et al. inferred that chondrule mesostasis was subjected to hydrothermal alteration in an asteroidal environment by protosolar water $\left(\mathrm{D} / \mathrm{H}=89 \pm 9 \times 10^{-6}\right)$. The hydrated pyroxenes did not undergo isotopic reequilibration with the hydrothermal water and retained the preaccretional interstellar isotopic signature $\left(\mathrm{D} / \mathrm{H}>200 \times 10^{-6}\right)$. These data indicate that at least two sources of water were intimately mixed in the solar nebula: protosolar and interstellar.

$\mathrm{K}$. Tomeoka described recent petrographic studies of CV3 chondrites and their dark inclusions. Dark inclusions experienced metasomatic alteration that resulted in replacement of their chondrules by fayalitic olivines. The latter are compositionally and microtexturally similar to matrix olivines in Allende that are believed to have formed by hightemperature condensation from an oxidized solar nebula gas. The chondrule pseudomorphs are crosscut by fayalitic olivine-nepheline veins, suggesting that alteration of the dark inclusions took place after their agglomeration and involved significant mobilization of Na. Contrary to expectations, Tomeoka finds that phyllosilicates in $\mathrm{CV}$ alteration assem- 
blages did preserve the orientation of precursor chondrule olivine to a fair degree. The metamorphic event that subsequently changed this phyllosilicate back to olivine similarly preserved this crystallographic orientation information. This result means that dark inclusions are even better recorders of precursor mineralogy than was previously recognized, lending further support to the idea that $\mathrm{CV}$ asteroidal aqueous alteration was far more pervasive than once thought.

J. Akai and S. Tari reported on results of their search for metamorphosed CM and CI chondrites, which are believed to have experienced aqueous alteration to various degrees before thermal metamorphism and dominate the current surfaces of the supposedly pristine C-, G-, B-, and F-type asteroids (Hiroi et al., 1993). Since the first three of these (B 7904, Y 86720, Y 82162) were recognized a decade ago, more than 10 metamorphosed carbonaceous chondrites have been discovered among the meteorites returned from Antarctica by Japanese expeditions. One might ask why all such meteorites have been found only among the Japanese collections; the answer probably concerns the lack of a similarly complete survey for the ANSMET and EUROMET collections.

R. Hutchison with coworkers reported on the differences in aqueous fluid compositions witnessed by the two unequilibrated ordinary chondrites Semarkona (LL3.0) and Tieschitz (H/L3:6). A third of chondrules in Tieschitz experienced in situ leaching and elemental redeposition to form secondary albite, nepheline, and unidentified, $\mathrm{Na}$-,Al-rich phases. Semarkona experienced more extensive aqueous alteration, resulting in formation of abundant smectite and minor calcite; evidence of large-scale elemental redistribution is absent. The observed compositional differences in bulk chemistry of matrix in Tieschitz and Semarkona (the former is significantly poorer in Si and $\mathrm{K}$ ) may reflect variations in primary silicate chemistry or postaccretional history.

In the final presentation in this session, E. Scott and coworkers explored the relationship between asteroidal metamorphism and aqueous alteration. Aqueous alteration, dehydration, and dry metamorphism can be considered a natural consequence of prograde metamorphism on a hydrous asteroid. These processes may have resulted in formation of various anhydrous minerals, including magnetite, fayalite, Ca-Fe-rich pyroxenes, grossular, wollastonite, andradite, nepheline, sodalite, and carbides; elemental redistribution; variations in $\mathrm{FeO}$ concentrations in olivine and pyroxene; normative olivine/pyroxene ratios; and metal abundances.

\section{ALTERATION OF CV3 CHONDRITES: NEBULAR OR ASTEROIDAL}

\section{Summarized by G. J. MacPherson and S. Weinbruch}

This session provided some of the liveliest discussion of the entire workshop. The participants were evenly split on the questions posed by the title of the session, and in gen- eral the only points of agreement were the diverse observations themselves - almost never on the interpretations.

Central to most of the debate was the model, summarized in the first talk by A. Krot and colleagues, that many $\mathrm{CV} 3$ chondrites (especially the oxidized subgroup) experienced metasomatic alteration to various degrees in the presence of aqueous solutions followed by mild temperature thermal dehydration. Products of this two-stage process are believed to include magnetite, Ni-rich metal and sulfides, fayalite $\left(\mathrm{Fa}>9_{0}\right), \mathrm{Ca}-\mathrm{Fe}$-rich pyroxenes, andradite, wollastonite, lath-shaped fayalitic olivines $\left(\mathrm{Fa}_{35-50}\right)$ that constitute the major portion of the meteorite matrices and dark inclusions, phyllosilicates found in chondrules, $\mathrm{Ca}$-Al-rich inclusions (CAIs) and dark inclusions, and widespread alkali-rich secondary mineralization of chondrules and CAIs. Supporting evidence includes (1) pseudomorphic replacement of chondrules and CAIs by fayalitic olivine; (2) veins of fayalite, nepheline, $\mathrm{Ca}$-Fe-rich pyroxenes and fayalitic olivines crosscutting fine-grained rims and matrices of $\mathrm{CV} 3$ chondrites and their dark inclusions that suggests the alteration postdated agglomeration; (3) O-isotopic compositions of magnetite and fayalite in Mokoia chondrules that plot along the terrestrial fractionation line with $\delta^{18} 0$ fayalite-magnetite fractionation $(-20 \%$ ) that is consistent with their formation with low-temperature formation in the presence of aqueous solutions; and (4) I-Xe isotopic data (presented by T. Swindle) that suggests the alkali-halogen metasomatism occurred too long after formation of the primary minerals, perhaps by as much as $10 \mathrm{~m} . y$. , to be consistent with a nebular origin. Also cited frequently during the session, but not actually presented at the workshop, was the discovery by Brearley of poorly graphitized $\mathrm{C}$ inclusions within the matrix olivine grains in Allende and its dark inclusions. The relatively low upper thermal stability limits of these phases is argued to mitigate against a high-temperature nebular origin for the host olivines. In an initial attempt to test the Krot et al. (1995) hypothesis, M. Petaev and M. Mironenko presented theoretical calculations of the results of water interacting with anhydrous assemblages, varying water/rock ratios and temperature. They compared their results with observed mineral assemblages in the meteorites, but the calculations were still too preliminary to reach firm conclusions. An experimental approach was taken by $\mathrm{K}$. Nomura and M. Miyamoto, who attempted to reproduce the secondary mineral assemblages in CAIs via reactions of CAI minerals (gehlenite, spinel, diopside) with strong reagents $\left(\mathrm{NaOH}, \mathrm{Na}_{2} \mathrm{CO}_{3}\right.$, and $\left.\mathrm{HCl}\right)$. The experiments produced hydrous phases not observed in natural CAIs; subsequent dehydration was a necessary step and even then the mineralogic match was problematic.

Among those arguing for nebular processing rather than asteroidal processing, $\mathrm{H}$. Palme pointed out that the very $\mathrm{Fe}$-rich (fayalitic) rims around olivines in CV3s have very steep compositional gradients that probably are diffusional in origin. As this requires high temperatures, and ample evidence elsewhere in these meteorites argues against global in 
situ high temperatures, Palme concluded that the fayalitic rims formed in a nebular environment where the gas was highly oxidizing. $X$. Hua and P. Buseck made similar arguments based on fayalitic halos around metal inclusions in $\mathrm{CV} 3$ olivines, again showing that very high temperatures are required to produce the halos by diffusion within reasonable timescales (« age of the solar system). They concluded that the halos predated incorporation of the host olivines into the present parent bodies, forming either by nebular heating or by processes occurring in a prior generation of parent body. G. MacPherson and A. Davis addressed the origin of the peculiar spindle-shaped (actually plates) olivine grains that characterize many CV3 matrixes. They noted that identical grains occur in multilayered rims around CAIs in those meteorites, and found both within individual layers and across layer boundaries highly unequilibrated mineral assemblages that cannot have formed in situ. They concluded that those layers, and the meteorite matrixes, are accretionary in origin and not the result of in situ dehydration of phyllosilicates as proposed by Krot and colleagues. M. Weisberg and M. Prinz, and $\mathbf{Y}$. Ikeda and $M$. Kimura, presented a variety of mineral chemical and textural evidence to argue that the observed properties of chondrules, matrixes, and dark inclusions in CV3s are best explained by nebular rather than asteroidal processes.

No resolution on these thorny issues was reached by the participants. Other than a basic agreement that the presence of phyllosilicates means at least some minor aqueous alteration occurred in CV3 chondrites, the only hint of progress was a fairly general recognition that any asteroidal processing of CV3s was necessarily local and limited in scale in order to account for the gross heterogeneities preserved in these rocks.

\section{MINERALOGICAL AND ISOTOPIC CONSTRAINTS ON THE SOLAR NEBULA AND ASTEROIDAL PROCESSING OF CHONDRITIC MATERIALS}

\section{Summarized by A. El Goresy and J. A. Nuth}

Reports given at this session mainly dealt with the diverse nebular and subsequent asteroidal modifications that can be constrained from the assemblages and their textures, $O$ isotopic compositions, theoretical and experimental studies of gas-grain chemistry, $O$ fugacity in the solar nebula, ${ }^{53} \mathrm{Mn}-{ }^{53} \mathrm{Cr}$ systematics in enstatite chondrites, evidence for early olivine condensates, evaporation behavior of minerals and silicate melts, and formation of single domain Fe particles.

B. Zanda and coworkers reported on the evolution of opaque and metal sulfide-bearing assemblages in chondrites. They characterized the textural relations and compositions of the metal-sulfide-oxide assemblages in order to decipher the various stages of the assemblage formation from the condensation phase, to chondrule formation, to parent-body pro- cessing. Finding pristine condensates became cumbersome because of the later modifications in the following processes. Zanda and coworkers believe that the smaller chondrules and the matrixes of primitive chondrites are the logical host for early metal-sulfide condensates. The assemblage encountered consists of troilite, pentlandite, awaruite, and cohenite with subordinate magnetite. In the matrix, Ni-bearing sulfides seem to be ubiquitous. In $\mathrm{CO} 3$ and $\mathrm{CM} 2$ chondrites the presence of pentlandite + pyrnhotite (instead of troilite + FeNi) is a direct result of the high $f_{S_{2}}$. Despite a careful search, metal condensates have not been located so far. Zanda and colleagues believe that there is no evidence for nebular magnetite. During chondrule formation it is believed that metal "regeneration" by desulfidization takes place in type 1 chondrules. Large metal grains lost from chondrules during this process become "metallic chondrules." Subsequently, $S$ recondenses on metallic chondrules and on metals in chondrule rims. During thermal metamorphism a relationship between the fine classification of the petrologic groups and the assemblages was found. In petrologic subtypes 3.0-3.5 metals and sulfide remain associated. Local migration of sulfides takes place. In petrologic subtypes 3.5-4, metal coalescence commences, and metal and sulfides separate. In petrologic types 4-6, the rounded shape of grains diminishes and development of very large metal grains is ubiquitous.

B. Fegley devoted his contribution to the lifetime of the gaseous solar nebula as deduced from theoretical models and experimental investigations of gas-grain chemistry. While a widely used lifetime calculated by $\mathrm{A}$. Cameron estimates $300,000 \mathrm{yr}$, astronomical observations of young stars, isotopic studies of meteorites, and theoretical models of accretionary disks suggest $0.1-10 \mathrm{~m} . \mathrm{y}$. Analysis using the simple collision theory (SCT) to quantify the kinetics of gas-grain reactions for troilite, magnetite, and hydrated silicates reveals that FeS formation is a rapid process (320 yr in the nebula). Experimental investigations on meteoritic $\mathrm{FeNi}$ metal at various $\mathrm{H}_{2} / \mathrm{H}_{2} \mathrm{~S}$ mixtures even at low $\mathrm{H}_{2} \mathrm{~S}$ concentrations $(25,50$, and $100 \mathrm{ppm}$ by volume) support the theoretical calculations. Fegley and D. Lauretta's experiments reveal more details about the variation of the $\mathrm{Ni}$ concentrations from the metal-sulfide interface to the sulfide $\mathrm{H}_{2} \mathrm{~S}$ gas interface, thus favoring the formation of pentlandite inclusions in pyrrhotite. In contrast, the SCT models predict that the magnetite formation needs $320,000 \mathrm{yr}$ in the nebula. It should, however, be more rapid in the higher-pressure subnebula. Fegley's experiments indicate that $\mathrm{Fe}_{3} \mathrm{O}_{4}$ forms by reaction of $\mathrm{Fe}$ with $\mathrm{H}_{2} \mathrm{O}$, although the rate is slower than that for FeS formation. Fegley concludes that it is unlikely that the bulk $\mathrm{Fe}_{3} \mathrm{O}_{4}$ formed in the nebula. The SCT models also predict that hydrate silicate formation (serpentine, talc) takes 4.5 b.y. in the solar nebula. The hydration process at near-vacuum conditions is very slow. However, hydrated silicates can form in subnebulae around Jupiter and Saturn. High pressures in these subnebulae should lead to faster reaction 
rates. In contrast, mica dehydration experiments reveal that water loss is more rapid than breakdown to the thermodynamically stable reaction products. Fegley reasons that formation of hydrated silicates inside parent bodies seems more plausible than by nebular gas-grain reactions.

Wasson advocated asteroidal aqueous alteration as the more plausible process to explain the ubiquitous occurrence of fayalitic rims around forsteritic olivines in chondrules and individual forsteritic grains in $\mathrm{CV} 3$ and ordinary chondrites. This process should also be responsible for the formation of phyllosilicates. Wasson argues that it is easier to oxidize metal or aqueously alter other phases in asteroids than in the solar nebula. In the parent bodies of a radius of $50 \mathrm{~km}$, $\mathrm{pH}_{2} / \mathrm{pH}_{2} \mathrm{O}$ ratios should be much lower than in the solar nebula, causing the stability fields of alteration phases to extend to high temperatures, and the $\mathrm{H}_{2} \mathrm{O}$ pressures are much higher, thus leading to higher reaction rates. $\mathrm{H}_{2} \mathrm{O}$ was probably the dominant volatile in asteroids. The internal pressure may have reached $1 \mathrm{~atm}$ at a depth of $1 \mathrm{~km}$ in a chondritic asteroid of $50 \mathrm{~km}$. Wasson reasoned that observations, mostly involving fayalite or magnetite, seem better understood in terms of aqueous alteration followed by the dehydration on asteroids (see below).

R. Clayton scrutinized the possibility of constraining the formational conditions of oxidized phases, like fayalitic rims, and hydrated phases (phyllosilicates) in chondrites by their $\mathrm{O}$-isotopic compositions. He stressed the fact that equilibration fractionations of $O$ isotopes between phases at the temperatures of molten silicates are generally less than 3 , whereas fractionations between mineral and water are commonly greater than 20 at $0^{\circ} \mathrm{C}$. Measurements of the $O$ isotopes in mineral constituents of carbonaceous chondrites lead to the conclusion that the initial dust component in the solar nebula was enriched in 160 relative to the larger gaseous reservoir by a factor of 70 . The high-temperature process leads to mixing lines in the $O$ three-isotope diagram. For CAIs and chondrules the lines have slopes close to 1 , thus reflecting the compositions of the two primary reservoirs. Oxygen-isotopic composition of chondrules in $\mathrm{H}, \mathrm{L}$, and $\mathrm{LL}$ chondrites follow a single, slope-1 mixing trend independent of the $\mathrm{Fe}$ group. This evidence indicates that chondrules in these groups acquired their isotopic compositions in high-temperature events in the nebula before accretion in their parent bodies. The low-temperature water-rock interaction that leads to the production of hydrous minerals ( $\mathrm{CI}$ and $\mathrm{CM}$ chondrites) produces large heavy isotope enrichment in $\mathrm{O}$. Fayalitic olivine in chondrules, dark inclusions, and matrixes have been explained by several authors to have resulted from dehydration of phyllosilicate precursors that were, in turn, formed by interaction of fluids and chondritic materials in the parent bodies. Clayton indicates that if the proposed phyllosilicates had been formed in low-temperature parentbody processes (like in $\mathrm{CI}$ and $\mathrm{CM}$ ), they should have acquired the heavy isotope enrichment characteristic of these processes. Subsequent dehydration would not erase this isotopic signature, since dehydration produces very small changes in $\mathrm{O}$-isotopic compositions. Clayton concludes that the observed O-isotopic compositions of these materials show no evidence of low-temperanure hydration. The reservoir interactions must have involved the nebular gas at temperatures high enough that the mass-dependent fractionation should be small.

M. Wadhwa and coauthors presented evidence for a ${ }^{53} \mathrm{Cr}$ excess in MAC 88136 (EL3) of 18,400\%. This excess was observed in large sulfides with high $\mathrm{Mn} / \mathrm{Cr}$ ratios. Wadhwa et al. examined two other enstatite chondrites (MAC 88184 and MAC 88180, both EL3) and found that they seemed to have different systematics, most probably due to diffusional redistribution. Examination of the ${ }^{53} \mathrm{Mn} /{ }^{55} \mathrm{Mn}$ in sphalerites in Indarch (E4) show two slopes, again indicating disturbed systematics. Comparison of the formation ages of the EL and $\mathrm{EH}$ chondrites based on $\mathrm{Mn} / \mathrm{Cr}$ ratios indicates that the EL parent body formed $\sim 3$ m.y. after the EH parent body.

K. Lodders and Fegley examined the problem of the $\mathrm{FeO}$ content of silicates in terms of changes in the $\mathrm{C} / \mathrm{O}$ ratio of restricted portions of the nebula during condensation. Lodders showed that if $O$ is removed from a solar composition gas (e.g., by loss of water ice into the jovian planets), then some reducing species ( $\mathrm{TiN}$ and $\mathrm{TiC}$ ) appear at $\mathrm{C} / \mathrm{O}<1$. If the $\mathrm{C} / \mathrm{O}$ is varied by the addition of $\mathrm{C}$ (e.g., a mass of carbonaceous dust equal to the silicate mass), then the reduced phases again appear, but at $\mathrm{C} / \mathrm{O}$ of almost 1 . In addition, no anomalies in the silicon isotopes have been observed as might be expected by the addition of SiC produced in AGB stars, although the addition of $\mathrm{SiC}$ might help to resolve the low $\mathrm{Mg} / \mathrm{Si}$ ratio observed in reduced meteorites. There are several ways to attain a reducing environment within the nebula, provided that the nebula was not homogeneous.

S. Weinbruch demonstrated that large forsterite grains separated from Allende via freeze/thaw are nebular condensates large enough to survive alteration in the Allende parent body. These large samples contain enrichments in $\mathrm{Ca}$, $\mathrm{Al}$, and $\mathrm{Ti}$ that some suggest represent an igneous origin for these grains. However, Weinbruch argues that these enrichments would be much higher if forsterite were crystallized from a melt, similar to the very low $\mathrm{Mn}$ abundance he reported, and contrary to the high REE abundances he observes, too high to have crystallized from a chondritic melt. These crystals indicate both that nebular cooling needed to be slow enough to form millimeter-sized grains and that the earliest condensates must have formed under oxidizing conditions.

H. Nagahara discussed petrographic signatures indicating the hydration and dehydration of olivine to phyllosilicates either in nebular gas or fluid. Gas phase hydration produces serpentine and brucite (simple hydration), while liquid-phase hydration results in the loss of both $\mathrm{Mg}$ and $\mathrm{Si}$. The dehydration of serpentine into a vacuum is rapid, having a highly 
disordered structure that slowly recrystallizes along epitaxial directions. In a fluid this recrystallization occurs along random directions. These observations are based on a series of experiments from $300^{\circ}$ to $800^{\circ} \mathrm{C}$ at pressures down to 10-9 bar for times of up to days. Dehydration is very rapid and shows a strong dependence on the total gas pressure.

J. Nuth and P. Withey demonstrated that single magnetic domain Fe grains can be produced via vapor-phase condensation in the absence of a magnetic field. These particles are on the order of $20-35 \mathrm{~nm}$ in diameter and are thermodynamically stable as dipole magnets. Their dipoles can initiate the coagulation of very-fine-grained materials that may have eventually formed chondrules or survived as meteorite matrix. If 20-50-nm-sized grains are observed in meteorite matrix, Nuth predicts that other grains can be found connected within the matrix.

\section{MODIFICATION OF CHONDRITIC COMPO- NENTS: WHEN, WHERE, AND HOW?}

\section{Summarized by S. S. Russell and J. N. Grossman}

This session reviewed how various chondritic constituents have been altered in the nebula and parent body and how the effects of alteration in these two environments can be distinguished. Materials discussed spanned the range of nebular and prenebular objects: presolar grains, CAIs, CAI rims, chondrules, plagioclase-bearing chondrules, matrix, and micrometeorites.

A theme of the session that all the participants deemed important was a discussion of how unaltered nebular material might be identified. Brearley described how the effects of metamorphism most rapidly affect the fine-grained matrix of meteorites, and so a search for pristine nebular material should focus on meteorites with unaltered matrixes. He suggested that indicators of pristine matrix include the presence of amorphous silicate groundmass, unequilibrated minerals, and the presence of a diverse collection of components. One meteorite that appears to be minimally altered is the unusual carbonaceous chondrite Acfer 094, discussed by A. Greshake. The matrix of Acfer 094 contains amorphous glass that Greshake proposed formed from condensation in a nebular or circumstellar environment, and may represent the precursor of other matrix components. Another candidate for relatively unaltered material is some chondritic interplanetary dust particles (IDPs), described by F. Rietmeijer. These particles may come from outer-belt asteroids that sampled mainly nebular dust and have not been altered as much as material sampled by our meteorite collections.

However, the speakers agreed that almost all chondritic material has been processed to some degree in a postaccretionary setting. For example, all the unequilibrated ordinary chondrites and some low-petrologic-type CO chondrites contain chondrules that have been metasomatized to form water- and halogen-rich, porous, bleached zones (J. Grossman and coworkers). The metasomatism is inferred to have occurred on the parent body, since it tends to occur only in places where the chondrule contacts matrix rather than another chondrule, suggesting that the matrix assisted the fluid flow.

The effects of parent-body metamorphism can, in some instances, be recognized by studying the changes that occur in meteorites of increasing petrologic grade. G. Huss showed that the lowest-petrologic-grade meteorites tend to contain higher amounts of interstellar diamond and $\mathrm{SiC}$ than their high-petrologic-grade counterparts, and demonstrated that these grains are absent in ordinary chondrites of petrologic type $>\sim 3.7$, clearly suggesting that parent-body metamorphism tends to destroy interstellar grains. For most meteorite groups, graphite and the diamond fraction that carries the noble gas component $\mathrm{P} 3$ is very sensitive to metamorphism, $\mathrm{SiC}$ is moderately resistant, and the majority of the diamond is most resistant. Other indicators of parent-body alteration are provided by CAIs. CAIs from higher petrologic type $\mathrm{CO} 3$ meteorites contain spinel that has a higher $\mathrm{Fe}$ content than spinel in low-petrologic-grade $\mathrm{COs}$, and melilite decreases in abundance with increasing petrologic type in these meteorites (S. Russell and MacPherson). These observations all show that parent-body effects, even in type 3 chondrites, can significantly change the primary meteorite mineralogy.

In addition to aqueous and thermal alteration of all petrologic grade meteorites in the parent body, the preaccretionary alteration of chondritic components was discussed. Examples of possible nebular processes include the formation of CAI rims. The formation of rims has been studied experimentally by $D$. Wark, who suggests that their formation requires temperatures of at least $1200^{\circ} \mathrm{C}$ for $20 \mathrm{hr}$, unequivocally indicating a nebular origin. Many other features of CAIs can be attributed to alteration in the nebula. An example is the formation of whisker-shaped crystals in CAI voids, which are suggestive of condensation from a gas (Russell and MacPherson). Nebular processes were also suggested to have affected presolar grains and plagioclase-rich chondrules. Huss suggested that the presolar grain assemblage of some meteorites suggests that nebular evaporative processes have taken place. $R$. Jones showed that olivine in plagioclase-rich chondrules from $\mathrm{CO} 3$ meteorites tends to have a higher fayalite content than the more common ferromagnesian chondrules from the same meteorite. She reasoned that this observation indicates that plagioclase-rich chondrules suffered $\mathrm{Fe}$ metasomatism in a nebular environment. While a nebular environment was widely accepted as the location for extremely high-temperature events such as CAI rim formation, the location of other processes, such as halogen metasomatism of CAIs, remains more controversial.

Clearly, chondritic constituents had a complex history and record many pre- and postaccretionary events. While many 
of these can be unraveled by looking at meteorites that have suffered differing degrees of alteration, the apparent lack of any truly pristine meteorites ensures that the relative importance of nebular and parent-body processes is still a subject of extremely active debate.

\section{PETROLOGIC AND CHEMICAL CONSTRAINTS ON ACCRETION AND ALTERATION OF CHONDRITIC MATERIALS}

\section{Summarized by R. H. Jones and D. S. Lauretta}

This session offered a diverse sampling of problems associated with the accretion process and postaccretion alteration. These included isotopic and petrologic constraints as well as theoretical modeling of processes affecting the early history of chondrites.

The session began with a talk given by I. Hutcheon that covered the available isotopic evidence from short-lived radionuclides. The ${ }^{26} \mathrm{Al},{ }^{53} \mathrm{Mn}$, and ${ }^{129} \mathrm{I}$ chronometers were reviewed and age estimates from the $\mathrm{Pb}-\mathrm{Pb}$ system were evaluated for comparison. Remarkably few data are available. Of those that exist, there is a problem identifying the event(s) that correspond to isotopic closure. Data relating to phosphate formation on ordinary chondrite parent bodies are the most robust. However, the apparent formation age of 2 $\mathrm{Ma}$ after CAIs overlaps with chondrule formation ages of at least 2-3 Ma after CAIs.

The second presentation, by J. Cuzzi, dealt with size selection and concentration of chondrules in a turbulent gaseous nebula. This is accomplished by numerical calculations of particle density fields resulting from turbulence in the nebula. These calculations suggest that chondrule-sized objects are preferentially concentrated in turbulent eddies. Sizefrequency distributions predicted from the model match those observed in chondrites. This implies that objects that were smaller or larger than chondrules were excluded from incorporation into parent bodies as a result of this process.

G. Kurat reminded us all that some chondrites such as Renazzo (CR2) contain a diverse population of unaltered and altered material in close proximity. The current spatial relationship may not reflect the original alteration environment. This is an important example of the need to consider preaccretionary alteration environments.

D. Sears discussed a model that had been proposed previously for chondrule formation and was extended to explain alteration processes. If chondrite material was held in a dynamic regolith environment, this may be a candidate for an environment in which gas-dust interactions commonly described as a "nebular" process could occur. He attempted to relate this environment to the wide variation of oxidation states and chemical composition of different chondrite groups.
M. Lipschutz reviewed the variety of processes that can be investigated using the relative abundances of labile trace elements. These data provide evidence for parent-body metamorphism in carbonaceous, ordinary, and enstatite chondrites with maximum temperatures experienced in the range $400^{\circ}$ to $<1000^{\circ} \mathrm{C}$.

\section{WHAT HAVE WE LEARNED ABOUT ASTEROIDAL AND NEBULAR PROCESSING OF CHONDRITIC MATERIALS, WHAT REMAINS UNRESOLVED, WHAT MUST BE DONE?}

\author{
Summarized by M. E. Zolensky
}

The final two talks of the workshop were intended to be preliminary summations of the evidence presented at the workshop for asteroidal and nebular (preaccretional) environments as distinct locations and sites for alteration of chondritic material. As such, these talks were obviously not polished presentations. Rather they were attempts to put a fine point on important workshop conflicts (many), agreements (!), and recommendations (most important).

P. Cassen made summary comments from the point of view of an astrophysicist, one who thinks mainly about the preaccretional period of solar system history. He reviewed the "known" properties of the solar nebula: (1) it went from hot to cold radially, vertically, and temporally; (2) solids and gas underwent substantial radial excursions during the planetbuilding epoch; (3) accumulation of solids started early and persisted; (4) weather happened; which was taken to include changes in humidity, oxidation state, and pressure as well as temperature. He identified the following main issues: (1) What were the embryonic mechanics of planet building? (2) What determined the compositions of the planets and meteorites? (3) What determined the distribution of water in the solar system? and (4) How were components preserved from one epoch to another? How were they mixed?

Cassen also recommended use of more specific terms for locations of processes. Rather than referring merely to asteroidal and nebular (or preaccretional), he listed more useful terms. Thus, rather than merely asteroidal, one should refer to processes occurring either (1) in situ; (2) somewhere else on the same asteroid, but still local; or (3) during a previous generation of asteroidal residence. He suggested that "nebular" alteration could instead be referred to occurring in either (1) the solar nebula, (2) within a collisional vapor cloud, (3) within an atmosphere, or (4) within the wind produced by a bipolar outflow of material. In reference to the current controversy on the scale of alteration on the CV3 parent body, he recommended research exploring the scale of the water plumbing system. He also speculated on which properties of a meteorite like Allende were truly primitive. Are $O$ isotopes, bulk chemistry, or CAIs truly relicts of the 
preasteroidal processes? Cassen suggested further exploration of the role of presolar material in chondrites. How true is the claim that isotopic systems can be used to see through the mess of secondary processing?

J. Kerridge then presented a summary from the point of view of an "asteroidist." He discussed three issues that he considered key: (1) the status of the Metzler et al. (1992) model for production of dust mantles in CM2 chondrites, (2) the status of the Krot et al. (1995) model for production of matrix in CV3 chondrites, and (3) other constraints on the nature of alteration in chondrites.

Regarding the first of these topics, Kerridge found the most persuasive evidence for preasteroidal alteration of $\mathrm{CM}$ chondrites to be (1) the disequilibrium mineral mixtures within "accretionary" mantles (Metzler et al., 1992; Bischoff, this workshop); (2) the presence of phyllosilicates in direct contact with unaltered glass (Metzler et al., 1992; Bischoff, this workshop); (3) unserpentinized olivines grains within partially serpentinized chondrules (Metzler et al., 1992; Bischoff, this workshop); and (4) survival of CAI alteration textures apparently too fragile to have withstood regolith recycling (Russell and MacPherson, this workshop).

Kerridge considered the most persuasive evidence for asteroidal alteration to be (1) observable mineral replacement relations (Zolensky, this workshop); (2) mineral intergrowths (Zolensky, this workshop); (3) Fe-rich aureoles (Hanowski and Brearley, this workshop); (4) bridging texures (Browning, this workshop); (5) relict chemical zoning (Zolensky, this workshop); and (6) the O-isotopic distribution between carbonate and phyllosilicates (Clayton, this workshop).

Kerridge then explored several of these lines of evidence. For example, a key observation of CM2 chondrites is the presence of disequilibrium mineral associations, e.g., hydrated and anhydrous ferromagnesian silicates in contact. He pointed out that the brecciation of these materials, and incomplete alteration seen by them, inevitably leads to disequilibrium mineral associations, regardless of the location of the alteration. Regarding the Metzler et al. (1992) model for preasteroidal formation of accretionary mantles, he showed an image of a carbonate crystal with an accretionary mantle (from $Y$ 791198), reminded the audience that the partial pressure of $\mathrm{CO}_{2}$ in the nebula was too low to permit its carbonate formation there, and concluded that at least some accretionary mantles must have formed on asteroids.

Kerridge then turned to the Krot et al. (1995) model for formation of CV3 matrix. He enumerated the following evidence supportive of this model: (1) the presence of fayalitic olivine pseudomorphs after phyllosilicates (Kojima et al., 1994; Krot et al., 1995); (2) fibrous olivine veins penetrate chondrule pseudomorphs (Kojima et al.. 1994); (3) fayalitic olivine veins cross-cut rims and matrix (Krot et al., 1995); (4) the presence of replacement textures after chondrules and mineral grains (Krot et al., 1995); (5) the presence of inclu- sions of pentlandite, chromite, and poorly graphitized $\mathrm{C}$ in olivine (Krot et al., 1995, Weisberg and Prinz, this workshop; Brearley, this workshop); (6) the presence of relict phyllosilicates in matrix (Krot et al., 1995); (7) veins of alteration products cross-cut inclusions (Krot et al., 1995); (8) hydrothermal experiment simulations yield secondary mineralization similar to $\mathrm{CV} 3$ chondrites (Nomura and Miyamoto, this workshop); (9) CV3 anhydrous mineralogy is consistent with the products of dehydration experiments (Nomura and Miyamoto, this workshop); (10) a 10-m.y. age range for $\mathrm{CV} 3$ alteration processes is long compared to nebular lifetime; (11) in particular, alkali/halogen metasomatism occurred $>5$ m.y. after CAI production (Swindle, this workshop).

There is observational evidence opposing the Krot et al. (1995) model: (1) The wide range of fayalite morphologies appears inconsistent with phyllosilicate dehydration (MacPherson and Davis; Weisberg and Prinz, this workshop); (2) preservation of mineral zoning and disequilibrium assemblages is inconsistent with metamorphic (dehydration) temperatures (MacPherson and Davis; Weisberg and Prinz; Ikeda and Kimura, this workshop); (3) stratigraphic control of metasomatic alteration products in rims is suggestive of accretion, not in situ alteration (MacPherson and Davis, this workshop); (4) no crystal intergrowths are present in rims and matrix (MacPherson and Davis; this workshop); (5) there is melting of some inclusions after alkali/halogen metasomatism; (6) there is no evidence for hydrous phases in dark inclusions (Kojima et al., 1994; Tomeoka, this workshop); (7) fayalitic olivine halos require solid-state diffusion at high temperature (Palme; Hua and Buseck, this workshop); (8) some fayalitic olivine clearly predates hydration (Weisberg and Prinz, this workshop); (9) fayalitic olivine is sometimes topotactically related to chondrule olivine (Weisberg and Prinz, this workshop); (10) there are amorphous rims on submicron olivines that might have formed by nebular irradiation (Weisberg and Prinz, this workshop); (11) survival of chondrule mesostasis apparently precludes an aqueous environment (Weisberg and Prinz, this workshop); (12) modeling indicates that alkali/halogen metasomatism did not involve an aqueous solution (Petaev and Mironenko, this workshop); (13) poorly graphitized C rims on metal apparently formed by catalytic disproportionation of $\mathrm{CO}$ (Keller, this workshop); (14) evidence suggests that aqueous alteration postdated metasomatism (nebular) in Mokoia (Kimura and Ikeda, this workshop); and (15) fayalitic olivine apparently interacted with the same gaseous $\mathrm{O}$ as CAIs, and shows no isotopic signature of low-temperature alteration (Clayton, this workshop).

These various pros and cons for the Krot et al. model clearly require further testing, since our understanding of $\mathrm{CV}$ genesis is so fundamental to our picture of the early solar system. 
Finally, Kerridge posed the following questions: Does condensation imply a global nebular (during cooling of a gaseous disk), localized nebular (e.g., following a transient heating event), or highly localized asteroidal process (e.g., in an impact-generated plume)? Is there any way to distinguish between these options?
References: Armstrong et al. (1982) Geochim. Cosmochim. Acta, 46, 575-596. Hiroi et al. (1993) Science, 261, 1016-1018. Kojima et al. (1994) Meteoritics, 28, 649-658. Krot et al. (1995) Meteoritics, 30, 748-775. Metzler et al. (1992) Geochim. Cosmochim. Acta, 56, 2873-2897. 


\section{List of Workshop Participants}

Junji Akai

Department of Geology

Faculty of Science

Niigata University

1 Karashi 2-no-cho, 8050

Niigata 950-21

JAPAN

Phone: 81-25-262-6186

Fax: 81-25-262-6194

E-mail: akai@sc.niigata-u.ac.jp

Richard D. Ash

Geophysical Laboratory

Carnegie Institution

5251 Broad Branch Road

Washington DC 20015

Phone: 202-686-4370

Fax: $202-364-8726$

E-mail: ash@gl.ciw.edu

Gretchen Benedix

Department of Geology and Geophysics

University of Hawai' i

2525 Correa Road

Honolulu HI 96822

Phone: 808-956-3151

Fax: 808-956-6322

E-mail: benedix@kahana.pgd.hawaii.edu

Adolf Bischoff

Institut fü Planetologie

Westfälische Wilhelms-Universität Münster

Wilhelm-Klemm-Strasse 10

48149 Münsier

GERMANY

Phone: 49-25I-833465

Fax: 49-251-839083

E-mail: bischoa@nwz.uni-muenster.de

Philip Bland

Department of Earth and Planetary Sciences

Western Australian Museum

Francis Street

Perth 6000

AUSTRALIA

Phone: 61-8-9427-2748

Fax: 61-8-9328-8686

E-mail:p.a.bland@open.ac.uk

Alan Boss

Department of Terrestial Magnetism

Carnegie Institution

5241 Broad Branch Road NW

Washington DC 20015

Phone: 202-686-4370 x4402

Fax: $202-364-8726$

E-mail: boss@dtm.ciw.edu
William V. Boynton

Lunar and Planetary Laboratory

Space Sciences Building \#92

University of Arizona

Tucson AZ 85721

Phone: 520-621-6941

Fax: $520-621.6783$

E-mail:wboynton@gammal.lpl.arizona.edu

Adrian Brearley

Northrop Hall, Room 313

Institute of Meteoritics

University of New Mexico

Albuquerque NM 87131-1126

Phone: 505-277-3842

Fax: 505-277-3577

E-mail: brearley@unm.edu

John Bridges

Department of Mineralogy

Natural History Museum

Cromwell Road

London SW7 SBD

UNITED KINGOM

Phone: 44-171-938-9313

Fax: 44-171-938-9268

E-mail: j.bridges@nhm.ac.uk

Lauren Browning

Hawai' i Institute of Geophysics and Planetology

School of Ocean and Earth Science and Technology

University of Hawai' $i$

2525 Correa Rood

Honolulu HI 96822

Phone: 808-956-390I

Fax: 808-956-6322

E-mail: lauren@kahana.pgd.hawaii.edu

Patti Jo Burkett

Mail Code SN2

NASA Johnson Space Center

Houston TX 77058

Phone: $281-483-5022$

Fax: $281-483-5347$

Marc Caffee

Lawrence Livermore National Laboratory

7000 East Avenue

P.O. Box 808

Livermore CA 94551

Phone: 510-423-8395

Fax: 510-422-1002

E-mail: caffee1@linl.gov 


\section{Pat Cassen}

Mail Code 170-25

Division of Geological and Planetary Sciences

California Institute of Technology

Pasadena CA 91125

Phone: 626-395-6195

Fax: 626-796-9823

E-mail: cassen@cosmic.arc.nasa.gov

Robert N. Clayton

Enrico Fermi Institute

University of Chicago

5640 Ellis Avenue

Chicago IL 60637

Phone: 773-702-7777

Fax: 773-702-5863

E-mail: r-clayton@uchicago.edu

Harold C. Connolly

Mail Stop 100-23

California Institute of Technology

Pasadena CA 91125

Phone: 626-395-6155

Fax: 626-683-0621

E-mail: vorlon@gps.caltech.edu

Ghislaine Crozaz

Campus Box 1169

Department of Earth and Planetary Sciences

Washington University

One Brookings Drive

St. Louis MO 63130

Phone: 314-935-6257

Fax: 314-935-4083

E-mail: gcw@howdy.wustl.edu

Jeff Cuzzi

Mail Stop 245-3

NASA Ames Research Center

Moffett Field CA 94035

Phone: 415-604-6343

Fax: 415-604-6779

E-mail: cuzzi@cosmic.arc.nasa.gov

Kimberly Cyr

3002 E. Hawthorne Street

Tucson $A Z 85716$

Phone: 520-621-1471

Fax: 520-621-4933

E-mail: kimberly@lpl.arizona.edu

Andrew M. Davis

Enrico Fermi Institute

University of Chicago

5640 S. Ellis Avenue

Chicago IL 60637

Phone: 773-702-5863

Fax: 773-702-9505

E-mail: a-davis@uchicago.edu

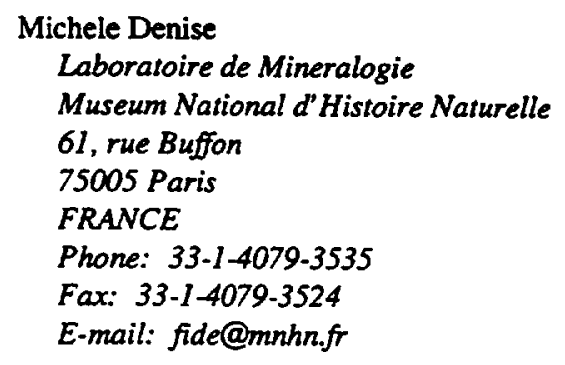

Ralf Dohmen

Institut für Mineralogie und Geochemie

Universität zu Köln

Zulpicherstrasse 49b

50674 Köln

GERMANY

Phone: 49-221-470-3238

Fax: 49-221-470-5139

E-mail: dohmen@min.uni-koeln.de

Gerlind Dreibus-Kapp

Abteilung Kosmochemie

Max-Planck-Institut für Chemie

Saarstrasse 23, Postfach 3060

Mainz D.55020

GERMANY

Phone: 49-6131-305395

Fax: 49-6131-371290

E-mail:dreibus@mpch-mainz.mpg.de

Peter Eberhardt

Physikalisches Institut

Universität Bern

Sidlerstrasse 5

CH-3012 Bern

SWITZERLAND

Phone: 41-31-631-8576

Fax: 41-31-631-4404-05

E-mail:eberhardr@phim.unibe.ch

Ahmed El Goresy

Max-Planck-Institut für Kernphysik

Postfach 103980

Saupfercheckweg 1

D-69029 Heidelberg

GERMANY

Phone: 49-6221-516475/476

Fax: 49-6221-516324

E-mail: goresy@selket.mpi-hd.mpg.de

Bruce Fegley

Campus Box 1169

Department of Earth and Planetary Sciences

Washington University

St. Louis MO 63130-4899

Phone: 314-935-4852

Fax: 314-935-4853

E-mail: bfegley@levee.wustl.edu 
Robert Fogel

Department of Mineral Sciences

American Museum of Natural History

West 79th Street at Central Park West

New York NY 10024

Phone: 212-769-5399

Fax: 212-769-5339

E-mail: bobby@amnh.org

Marina Fomenkova

Campus Box 0111

Center for Astrophysics and Space Sciences

University of California

San Diego CA 92093-0111

Phone: 619-534-6163

Fax: 619-534-7051

E-mail:marifo@cassir.ucsd.edu

Joe I. Goldstein

College of Engineering

University of Massachusetts

125 Marston Hall

Amherst MA 01003

Phone: 413-545-0300

Fax: 413-545-0724

E-mail: jig0@ecs.umass.edu

Cyrena A. Goodrich

Max-Planck-Institut fur Chemie

Postfach 3600

Mainz D-55020

GERMANY

Fax: 49-6131-371290

E-mail: goodrich@mpch-mainz.mpg.de

Monica M. Grady

Department of Mineralogy

Natural History Museum

Cromwell Road

London SW7 SBD

UNITED KINGDOM

Phone: 44-171-938-9445

Fax: 44-171-938-9268

E-mail: mmg@nhm.ac.uk

Ansgar Greshake

Museum für Naturkunde

Humboldt Universität zu Berlin

Invalidenstrasse 43

Berlin D.10115

GERMANY

Phone: 49-30-2093-8559

Fax: 49-30-2093-8565

E-mail: ansgar.greshake@rzhu-berlin.de
Jennifer A. Grier

Lunar and Planetary Laboratory

Space Sciences Building

University of Arizona

Tucson AZ 85721

Phone: 520-621-1507

Fax: 520-621-4933

E.mail: jgrier@lpl.arizona.edu

Jeffrey N. Grossman

Mail Stop 923

U.S. Geological Survey

954 National Center

Reston VA 20192

Phone: 703-648-6184

Fax: 703-648-6383

E.mail: jgrossman@usgs.gov

Sue Hallenbeck

Mail Code 691

Astrochemistry Branch

NASA Goddard Space Flight Center

Greenbelt MD 20771

Phone: 301-286-1548

Fax: 301-286-0212

E-mail: shallenbeck@lepvax.gsfc.nasa.gov

Nicolaus Hanowski

Northrop Hall 313

Department of Geology

Institute of Meteoritics

University of New Mexico

Albuquerque NM 87131

Phone: 505-277-5444

Fax: $505-277.3577$

E-mail: magell@unm.edu

Ko Hashizume

Department of Earth and Space Sciences

Faculty of Science

Osaka Universiry

Toyonaka Osaka 560

JAPAN

Phone: 81-6-850-5497

Fax: 81-6-850-554l

E-mail: kohash@ess.sci.osaka-u.ac.jp

Klaus Heide

Friedrich-Schiller-Universität

Institut Geowissenschafien

Burgweg 11

O7749 Jena

GERMANY

Phone: 49-03641-630-236

Fax: 49-03641-630-281

E-mail: ckh@rz.uni-jena.de 
Ulich Herpers

Abteilung Nuklearchemie

Universität zu Köln

Otto-Fischer-Strasse 12-14

Köln D-50674

GERMANY

Phone: 49-221-4701-3219

Fax: 49-221-4705115

E-mail: ulrich.herpers@uni-koeln.de

Roger H. Hewins

Department of Geological Sciences

Rutgers University

610 Taylor Road

Piscataway NJ 08854-8066

Phone: 732-445-3232

Fax: 732-445-3374

E-mail: hewins@rci.rutgers.edu

Charles Hibbitts

Planetary Geosciences Division

University of Hawai' $i$

2029 Kakela Road

Honolulu HI 96822

Phone: 808-956-3152

Fax: 808-956-6322

E-mail: hibbitts@kahana.pgd.hawait.edu

Yong Hong

Wilson Hall 108

Department of Earth and Planetary Sciences

Washington University

One Brookings Drive

St. Louis MO 63130

Phone: 314-935-7595

Fax: 314-935-736I

E-mail: yhong@levee.wustl.edu

Xin Hua

Campus Box 871404

Deparment of Geology and Chemistry

Arizona State University

Tempe AZ 85287-1404

Phone: 602-965-7250

Fax: 602-965-8102

E-mail: huaxin@asu.edu

Gary Huss

Mail Code 170-25

Division of Geological and Planetary Sciences

California Institute of Technology

Pasadena CA 91125

Phone: 626-395-6134

Fax: 626-568-0935

E-mail: ghuss@gps.caltech.edu
Ian D. Hutcheon

Mail Code L-23I

Lawrence Livermore National Laboratory

P.O. Box 808

Livermore CA 94551

Phone: 510-422-4481

Fax: 510-422-3160

E-mail: hutcheonl@llnl.gov

Robert Hutchison

Mineralogy Department

Natural History Musewn

Cromwell Road

London SW7 SBD

UNITED KINGDOM

Phone: 44-171-938-8866

Fax: 44-171-938-9268

E-mail: robh@nhm.ac.uk

Yukio Ikeda

Department of Earth Sciences

Ibaraki University

Bunkyo, 2-1-1

Mito 310

JAPAN

Phone: $81-29-228-8387$

Fax: 81-29-228-8405

Emil Jagoutz

Max-Planck-Institut für Chemie

P.O. Box 3060

Saarstrasse 23

Mainz D-55122

GERMANY

Phone: 49-6131-305381

Fax: 49-6131-371290

E-mail: jagoutz@mpch-mainz.mpg.de

Rhian Jones

Northrop Hall

Institute of Meteoritics

University of New Mexico

Albuquerque NM 87131-1126

Phone: 505-277-1643

Fax: 505-277-3577

E-mail: rjones@unm.edu

Klaus Keil

Hawai' $i$ Institute of Geophysics and Planetology

University of Hawai' $i$

2525 Correa Road, \#131

Honolulu HI 96822

Phone: 808-956-8761

Fax: 808-956-3188

E-mail: keil@kahana.pgd.hawaii.edu 
John F. Kerridge

Box 0317

Department of Chemistry

University of California at San Diego

La Jolla CA 92093-0317

Phone: 619-534-0443

Fax: 619-534-7441

E-mail: jkerridg@ucsd.edu

Makoto Kimura

Institute of Astrophysics and Planetary Sciences

Ibaraki University

Bunkyo 2-1-1

Mito Ibaraki 310

JAPAN

Phone: $81-29-228-8388$

Fax: 81-29-228-8405

E-mail: kimura@mito.ipc.ibaraki.ac.jp

Noriko Kita

Geochemistry Department

Geological Survey of Japan

1-1-3 Higashi

Tsukuba Ibaraki 305

JAPAN

Phone: 81-298-54-3558

Fax: 81-298-54-3533

E-mail: noriko@gsj.go.jp

Joem Koblitz

MetBase

Im Neuen Felde 16

D-28870 Fischerhude

GERMANY

Phone: 49-4293-1464

Fax: 49-4293-1494

E-mail::jkoblitz@physik.uni-bremen.de

Alexander Krot

Institute of Geophysics and Planetology

University of Hawai' i

2525 Correa Road

Honolulu HI 96822

Phone: 808-956-3900

Fax: 808-956-6322

E-mail: sasha@pgd.hawaii.edu

Gero Kurat

Naturhistorisches Museum

Postfach 417

A-1014 Vienna

AUSTRIA

Phone: 43-1-52177-263

Fax: 43-1-52177-264

E-mail:gero.kura!@univie.ac.at
Dante Lauretta

Department of Geology

Arizona State University

Tempe AZ 85287-1404

Phone: 602-965-7250

Fax: 602-965.8102

E-mail: dante.lauretta@asu.edu

Laurie Leshin

Department of Earth and Space Sciences

University of California, Los Angeles

595 Circle Drive East

Los Angeles CA $90095-1567$

Phone: $310-825-5505$

Fax: 310-825-2779

E-mail: laurie@oro.ess.ucla.edu

Ingo Leya

Zentrum für Strahlenschutz

Universität Hannover

Am Kleinen Felde 30

Hannover 30167

GERMANY

Phone: 49-511-762-3327

Fax: 49-511-762-3319

E-mail: leya@zsr.uni-hannover.de

Michael E. Lipschutz

BRWN/WTHR Chemistry Building

Department of Chemistry

Purdue University

West Lafayette IN 47907-1393

Phone: 765-494-5326

Fax: 765-494-0239

E-mail: rnaapuml@vm.cc.purdue.edu

Katharina Lodders

Campus Box 1169

Department of Earth and Planetary Science

Washington University

St. Louis MO 63130-4899

Phone: 314-935-4851

Fax: 314-935-4853

E-mail: lodders@levee.wustl.edu

Gary Lofgren

Mail Code SN4

NASA Johnson Space Center

Houston TX 77058

Phone: $281-483-6187$

Fax: $281-483-5276$

E-mail: gary.e.lofgren1@jsc.nasa.gov 
Gunter Lugmair

Abteilung Kosmochhemie

Max-Planck-Institut für Chemie

J. J. Becherweg 27

Mainz D.55128

GERMANY

Phone: 49-6131-305231

Fax: 49-6131-371290

E-mail: lugmair@mpch-mainz.mpg.de

\section{Glenn MacPherson}

NHB-119

Department of Mineral Sciences

Smithsonian Institution

Washington DC 20560

Phone: 202-357-2260

Fax: $202-357-2476$

E-mail: glenn@glennm.sl.edu

Kenji Matsuoka

Department of Earth and Planetary Sciences Kyushu University

1-10-6 Hakozaki

Higashi-ku Fukuoka City

JAPAN

Phone: 81-92-642-2670

Fax: 81-92-642-2684

E-mail: matsuoka@geo.kyushu-u.ac.jp

Kevin McKeegan

Department of Earth and Space Sciences

University of California, Los Angeles

405 Hilgard Avenue

Los Angeles CA 90095-1567

Phone: 310-825-3580

Fax: $310-825-2779$

E-mail: kdm@ess.ucla.edu

Rolf Michel

Zentrum für Strahlenschutz

Universität Hannover

Am Kleinen Felde 30

30167 Hannover

GERMANY

Phone: 49-511-762-3311/3312

Fax: 49-511-762-3319

E-mail: Michel@mbox.zsr.uni-hannover.de

Smail Mostefaoui

Max-Planck-Institut

Postfach 103980

Saupfercheckweg 1

Heidelberg 69029

GERMANY

Phone: 49-6221-516-476

Fax: 49-6221-516-324

E-mail: smail@pluto.mpi-hd.mpg.de
Hiroko Nagahara

Geological Institute

University of Tokyo

Hongo, Tokyo 113

JAPAN

Phone: 81-3-3812-2111 $\times 4508$

Fax: 81-3-3815-9490

E-mail: hiroko@geol.s.u-tokyo.ac.jp

Tomoki Nakamura

Department of Earth and Planetary Sciences

Faculty of Science

Kyushu University

Hakazaki Fukuoka 812-81

JAPAN

Phone: 81-92-641-2670

Fax: 81-92-642-2684

E-mail: tomoki@planet.geo.kyushu-u.ac.jp

Koji Nomura

Mineralogical Institute

Graduate School of Science

University of Tokyo

Hongo Bunkyo-ku

Tokyo 113

JAPAN

Phone: 81-3-3812-2111 $\times 4543$

Fax: $81-3-3816-5714$

Marc D. Norman

School of Earth Sciences

Macquarie University

North Ryde NSW 2109

AUSTRALIA

Phone: 61-2-9850-8258

Fax: 61-2-9850-8428

E-mail: marc.norman@mg.edu.au

Joseph Nuth

Mail Code 691

Astrochemistry Branch

NASA Goddard Space Flight Center

Greenbelt MD 20771

Phone: 301-286-9467

Fax: 301-286-1683

E-mail: nuth@gsfc.nasa.gov

Ryuji Okazaki

Kyushu University

1-10-6 Hakozaki

Hiugash-ku

Fukuoka City

JAPAN

Phone: 92-642-2670

Fax: 92-642-2680

E-mail: okazaki@geo.kyushu-u.ac.jp 
Herbert Palme

Institut für Mineralogie and Geochemie

Universität zu Köln

Zulpicherstrasse $49 b$

50674 Köln

GERMANY

Phone: 49-221-470-3198/2238

Fax: 49-221-470-5199

E-mail: palme@min.uni-koeln.de

Michail Petaev

Mail Stop 52

Harvard-Smithsonian Center for Astrophysics 60 Garden Street

Cambridge MA 02138

Phone: 617-495-7275

Fax: 617-495-7001

E-mail: mpetaev@cfa.harvard.edu

Christof Petry

Institut für Mineralogie und Geochemie

Universität zu Köln

Zulpicherstrasse $49 b$

50674 Köln

GERMANY

Phone: 49-221-470-3190

Fax: 49-221-480-5199

E-mail: petry@min.uni-koeln.de

Heide Prager

Max-Planck-Institut für Chemie

Saarstrasse 23

Postfach 3060

Mainz D-55122

GERMANY

Phone: 49-6131-305-231

Fax: 49-6131-371290

E-mail: prager@mpch-mainz.mpg.de

Martin Prinz

Department of Earth and Planetary Sciences

American Museum of Natural History

New York NY 10024

Phone: 212-769-5381

Fax: 212-769-5339

E-mail: prinz@amnh.org

Arch Reid

Department of Geosciences

University of Houston

Housion TX 77204-5503

Phone: 713-743-3404

Fax: 713-748-7906

E-mail: areid@uh.edu
Frans Rietmeijer

Northrop Hall

Department of Earth and Planetary Sciences

University of New Mexico

Albuquerque NM 87131

Phone: 505-277-573314209

Fax: 505-277-8843

E-mail: fransjmr@unm.edu

Andrew S. Rivkin

Lunar and Planetary Laboratory

University of Arizona

1629 E. University Boulevard

Tucson AZ 85721-0092

Phone: 520-621-1507

Fax: 520-621-4933

E-mail: asrivkin@lpl.arizona.edu

François Robert

Laboratoire de Mineralogie

Université Paris

61 Rue de Buffon

75005 Paris

FRANCE

Phone: 33-1-4079-3542

Fax: 33-1-4079-35-24

E-mail: robert@mnhn.fr

Linda Rowan

Science Editorial

1200 New York Avenue

Washington DC 20005

Phone: 202-326-6528

Fax: 202-408-1256

E-mail: lrowan@aaas.org

Sara Russell

Department of Mineralogy

Natural History Museum

Cromwell Road

London SW7 SBD

UNITED KINGDOM

Phone: 44-171-938-8866

Fax: 44-171-938-9268

E-mail: srussell@volcano.si.edu

Tamara Ruzmaikina

Lunar and Planetary Laboratory

University of Arizona

Tucson AZ 85721

Phone: 520-621-1798

Fax: 520-621-4933

E-mail: tamara@lpl.arizona.edu 
Ian Sanders

Department of Geology

Trinity College

Dublin 2

IRELAND

Phone: 353-1-608-1252

Fax: 353-1-671-1199

E-mail: isanders@tcd.ie

\section{Edward Scott}

Hawai' $i$ Institute of Geophysics and Planetology

University of Hawai' $i$

2525 Correa Road

Honolulu HI 96822

Phone: 808-956-3955

Fax: 808-956-6322

E-mail: escotr@pgd.hawaii.edu

Derek W. Sears

Department of Chemistry and Biochemistry

University of Arkansas

Fayerteville AR 72701

Phone: 501-575-5204

Fax: 501-575-7778

E-mail: cosmo@uafsysb.uark.edu

Gregory A. Smith

Institute of Geophysics and Planetology

University of Hawai' $i$

2525 Correa $R d$

Honolulu HI 96822

Phone: 808-956-3158

Fax: 808-956-6322

E-mail: gsmith@pgd.hawaii.edu

Gopalan Srinivasan

Mail Code 170-25

Division of Geological and Planetary Sciences

California Institute of Technology

Pasadena CA 91125

Phone: 626-395-6204

Fax: 626-796-9823

E-mail: srini@gps.caltech.edu

Thomas Stelzner

Institut für Geowissenchafter

Universität Jena

Burgweg II

o7749 Jena

GERMANY

Phone: 49-3-641-630-225

Fax: 49-3-641-630-281

E-mail: cto@rt.uni-jena.de
Thomas Stephan

Institut für Planetologie

Universität Münster

Wilhelm-Klemm-Strasse 10

48149 Münster

GERMANY

Phone: 49-251-8339-050

Fax: 49-251-8339083

E-mail: stephan@nwz.uni-muenster.de

Timothy D. Swindle

Lunar and Planetary Laboratory

University of Arizona

1629 E. University Boulevard

Tucson AZ 85721-0092

Phone: 520-621-4128

Fax: 520-621-4933

E-mail: tswindle@lpl.arizona.edu

Jeffrey Taylor

Planetary Geosciences Division

University of Hawai' $i$

2525 Correa Road

Honolulu HI 96822

Phone: 808-956-3899

Fax: 808-956-6322

E-mail: gjtaylor@pgd.hawaii.edu

Mark H. Thiemens

Box 0356

Department of Chemismy

University of California, San Diego

9500 Gilman Drive

La Jolla CA 92093-0356

Phone: 619-534-6732

Fax: 619-822-0389

E-mail:mhr@chem.ucsd.edu

Kazushige Tomeoka

Department of Earth and Planetary Sciences

Faculty of Science

Kobe Universiny

Nada, Kobe 657

JAPAN

Phone: $81-78-803-0578$

Fax: 81-78-803-0490

E-mail: tomeoka@shidaharal.planet.kobe-u.ac.jp

Michael A. Velbel

206 Natural Science Building

Department of Geological Sciences

Michigan State University

East Lansing MI 48824-1115

Phone: 517-353-5273

Fax: 517-353-8787

E-mail:velbel@pilot.msu.edu 
Meenakshi Wadhwa

Department of Geology

The Field Museum

Roosevelt Road at Lakeshore Drive

Chicago IL 60605

Phone: $312-922-9410 \times 643$

Fax: 312-922-9566

E-mail: wadhwa@fmppr.fmnh.org

Robert M. Walker

Campus Box 1105

McDonnell Center for Space Sciences

Washington University

One Brookings Drive

St. Louis MO 63130-4899

Phone: 314-935-6257

Fax: 314-935-4083

E-mail: rmw@howdy.wustl.edu

Heinrich Wänke

Max-Planck-Institut für Chemie

Becherweg 27

Mainz D-55128

GERMANY

Phone: 49-6131-305-230

Fax: 49-6131-371290

E-mail: waenke@mpch-mainz.mpg.de

David Wark

43 Eirene Street

Yarraville

Victoria 3013

AUSTRALIA

Phone: 613-9731-9444

Fax: 613-9369-5941

E-mail: paul@pctraining.com.au

John T. Wasson

Institute of Geophysics

University of California

Los Angeles CA 90095.1567

Phone: 310-825-1986

Fax: 310-206-3051

E-mail: wasson@igpp.ucla.edu

Stephan Weinbruch

Department of Material Sciences

Technical University of Darmstadt

Petersenstrasse 23

Darmstadt D-64287

GERMANY

Phone: 49-6151-166376

Fax: 49.6151-166378

E-mail: drgd@hrzpub.th-darmstadt.dr
Michael K. Weisberg

Department of Earth and Planetary Sciences

American Museum Natural History

New York NY 10024

Phone: 212-769-5385

Fax: 212-769-5339

E-mail: mkw@amnh.org

George W. Wetherill

Department of Terrestrial Magnetism

Carnegie Institution

5241 Broad Branch Road NW

Washington DC 20015

Phone: 202-686-4370 x4375

Fax: 202-364-8726

E-mail:wetherill@eros.ciw.edu

James Whitby

Williamson Building

Department of Earth Sciences

Manchester University

Oxford Road

Manchester M13 9PL

UNITED KINGDOM

Phone: 44-0161-275-3842

Fax: 44-0161-275-3947

E-mail: jwhitby@fsl.ge.man.ac.uk

Dieter Wolf

Institut für Mineralogie und Geochemie

Universität zu Köln

Zulpicherstrasse $49 b$

50674 Köln

GERMANY

Phone: 49-221-470-6112

Fax: 49-221-480.5199

E-mail: d.wolf@min.uni-koeln.de

Stephen F. Wolf

Chemical Technology Division/205

Argonne National Laboratory

9700 South Cass Ave.

Argonne IL 60439-4837

Phone: 630-252-6497

Fax: 630-252-4771

E-mail:wolf@cmt.anl.gov

Dorothy Woolum

Mail Stop 170-25

Physics Department

California State University

Fullerton CA 92634

Phone: 714-278-4828

Fax: 714-449-5810

E-mail: woolum@legs.gps.caltech.edu 
Toru Yada

Kyushu University

1-10-6 Hakozaki

Higashi-Ku

Fukuoka-Shi

JAPAN

Phone: 81-92-640-1101

Fax: $81-92-642-2680$

E-mail: yada@planet.geo.kyushu-u.ac.jp

Akira Yamaguchi

National Institute for Research in Inorganic Materials

1-1 Namiki

Tsukuba 305 Ibaraki

JAPAN

Phone: 81-298-51-3351 $x 2629$

Fax: $81-298-51-2768$

E-mail: yamaguchi@nirim.go.jp

\section{Keizo Yanai}

Department of Environmental and Planetary Geosciences Faculty of Engineering

Iwate University

4-3-5 Ueda

Morioka Iwate 020

JAPAN

Phone: 019-621-6438

Fax: 019-621-6459
Brigitte Zanda

Laboratoire de Mineralogie

Muséum National d'Histoire Naturelle

61, rue Buffon

75005 Paris

FRANCE

Phone: 33-1-4079-3533

Fax: 33-1-4079-3524

E-mail: meteor@mnhn.fr

Michael Zolensky

Mail Code SN2

NASA Johnson Space Center

Houston TX 77058

Phone: 281-483-5128

Fax: 281-483-5347

E-mail: michael.e.zolenskyI@jsc.nasa.gov 